\title{
SÍNTESE DO BUTIRATO DE N-BUTILA EMPREGANDO LIPASE MICROBIANA IMOBILIZADA EM COPOLÍMERO DE ESTIRENO-DIVINILBENZENO
}

\author{
Pedro Carlos de Oliveira, Gizelda Maria Alves, Heizir Ferreira de Castro* \\ Departamento de Engenharia Química - Faculdade de Engenharia Química de Lorena - CP 116 - Lorena - SP \\ Lucia Helena Innocentini Mei \\ Departamento de Ciência e Tecnologia de Materiais - Faculdade de Engenharia Química - Universidade de Campinas - CP 6066 - \\ Campinas - SP
}

Recebido em 14/9/99; aceito em 3/1/00

\begin{abstract}
SYNTHESIS OF BUTYL BUTYRATE BY MICROBIAL LIPASE IMMOBILIZED ONTO STYRENE-DIVINYLBENZENE COPOLYMER. This work investigates the reaction parameters of an immobilized lipase in the esterification reaction of n-butanol and butyric acid. Microbial lipase from Candida rugosa was immobilized onto styrene-divinylbenzene copolymer (STY-DVB) and subsequently introduced in an organic medium containing substrates in appropriate concentrations. Heptane was selected as solvent on the basis of its compatibility with the resin and the enzyme. The influence of molar ratio of acid to alcohol, amount of immobilized lipase and temperature on the butyl butyrate formation was determined. The results were compared with those achieved with free lipase and Lipozyme (commercially immobilized lipase) under the same operational conditions.
\end{abstract}

Keywords: lipase; organic solvent; immobilization; styrene-divinylbenzene copolymer; butyl butyrate.

\section{INTRODUÇÃO}

Embora nos últimos anos, a utilização de enzimas na indústria esteja aumentando rapidamente, ainda existe um grande campo para a sua expansão. Novas enzimas vão criando oportunidades e, em alguns ramos da indústria a utilização das enzimas está apenas começando. Um exemplo típico é uso de enzimas em síntese orgânica ${ }^{1-4}$.

Como é de conhecimento, até pouco tempo, havia a concepção de que as enzimas tinham pouca utilidade em síntese orgânica, devido principalmente à idéia preconcebida de que somente o meio aquoso era propício para manter a conformação estrutural de uma enzima cataliticamente ativa. Entretanto, sabe-se atualmente que, muitas enzimas (ou complexos enzimáticos) são cataliticamente ativas em ambientes hidrofóbicos naturais com eficiência similar àquela encontrada em soluções aquosas, ou em certos casos, até superior ${ }^{2,5}$. Acredita-se, que as enzimas sejam cataliticamente ativas em meio orgânico porque elas permanecem na sua conformação original. A incapacidade da proteína de se desdobrar em meio não aquoso devese em parte ao fato das interações eletrostáticas entre os grupos integrantes da enzima serem aumentadas em solventes orgânicos, devido à baixa constante dielétrica da maioria dos solventes e também ao aumento do número de ligações de hidrogênio intramoleculares ${ }^{6}$. Isto é importante, pois o equilíbrio termodinâmico de muitos processos, como por exemplo, a síntese de ésteres, só ocorre em ausência de água. Em síntese orgânica, existem inúmeras vantagens no uso de enzimas que apresentam especificidade significativas para a formação de produto de tal forma que, custo de separação, purificação e tratamento de resíduos sejam minimizados ${ }^{4-7}$.

Um grande número de trabalhos nesta área pode ser encontrado na literatura especializada, tendo em vista o interesse científico demonstrado por diversos grupos de pesquisa, no sentido de elucidar as propriedades e o comportamento de enzimas em meios não aquosos. Conseqüentemente, o número de rotas de síntese que incorporam um passo enzimático torna-se

*e-mail: decastro@easygold.com.br cada vez maior. Bem ilustrativos são os trabalhos de revisão de literatura ${ }^{3,4,7,8}$ que reúnem exemplos importantes, sob o ponto de vista de síntese orgânica, de reações catalisadas por diferentes classes de enzimas.

Entre os processos químicos de maior interesse industrial estão as reações catalisadas pelas lipases, as quais representam aproximadamente $20 \%$ das biotransformações realizadas atualmente ${ }^{6}$.

As lipases (triacilglicerol hidrolases EC 3.1.1.3) catalisam ambas as reações de hidrólise e síntese de éster a partir de glicerol e ácidos graxos de cadeias longas. Essas reações usualmente são processadas com alta regio e/ou enantiosseletividade, tornando as lipases um importante grupo de biocatalisadores. As razões desse enorme potencial biotecnológico das lipases incluem fatos relacionados com: i) sua alta estabilidade em solventes orgânicos; ii) não requerem a presença de cofatores; iii) possuem uma larga especificidade pelo substrato e, iv) exibem uma alta enantiosseletividade ${ }^{9-12}$.

Embora sua função natural seja a de quebrar as ligações de éster de triacilgliceróis com o consumo de moléculas de água (hidrólise), as lipases são também capazes de catalisar a reação reversa sob condições microaquosas, como por exemplo, a formação de ésteres a partir de álcoois e ácidos carboxílicos. Estes dois processos básicos podem ser combinados numa seqüência lógica para efetuar reações de interesterificação (acidólise, alcoólise e transesterificação), dependendo dos reagentes empregados ${ }^{10-12}$.

Para que a biotransformação possa competir com a produção química otimizada, alguns pontos de natureza técnica devem ser considerados. A imobilização da lipase, por exemplo, é um fator limitante na economicidade do processo. Além disso, as lipases, devido a sua natureza protéica, podem sofrer ao longo de uma reação um processo de desnaturação com perda progressiva da atividade funcional. Por meio da imobilização em suportes sólidos, entretanto, pode ocorrer um aumento na estabilidade do catalisador, prolongando sua vida útil. A imobilização facilita a recuperação da enzima do meio reacional, possibilitando sua posterior reutilização ${ }^{12}$

Há uma vasta quantidade de trabalhos na literatura que tratam das diferentes técnicas de imobilização de lipases, caracterização 
dos complexos ativados e aplicações em reações que se processam em meios aquosos e não aquosos. Uma grande variedade de materiais naturais, sintéticos orgânicos ou inorgânicos, com diferentes características de tamanho, forma e densidade, foram estudados para a imobilização de lipases ${ }^{13-18}$.

Estudos comparativos mostram diferenças acentuadas no desempenho de lipases imobilizadas nos vários suportes, e evidenciam que apesar das várias experiências reportadas na literatura, a imobilização de lipases ainda é um desafio complexo, uma vez que a extensão da imobilização depende da estrutura da enzima, método de imobilização, e do tipo de suporte $^{13,15}$. Em muitos casos, suportes que proporcionam uma elevada atividade e estabilidade da enzima, apresentam sérias limitações de resistência mecânica e de queda de fluxo do substrato, que os tornam inviáveis para a utilização em alguns tipos de reatores ${ }^{12,16}$.

Dados da literatura sugerem que suportes porosos com grande superfície interna ativada, com densas camadas de grupos altamente hidrofóbicos, podem ser reconhecidos pelas lipases, em nível molecular, como interfaces sólidas. Desta maneira, as lipases podem ser imobilizadas em tais suportes levando a "estruturas imobilizadas abertas" 17 . Além disso, estudos detalhados do sítio ativo das lipases têm relevado uma hidrofobicidade marcante das lipases comerciais ${ }^{15}$ direcionando desta forma a seleção de suportes hidrofóbicos ${ }^{12}$ para garantir uma maior interação da lipase com a matriz selecionada.

Ente os suporte hidrofóbicos considerados na imobilização de lipases, as matrizes poliméricas como Amberlite (XAD2, XAD4, XAD7 e XAD8), poli (ácido carboxílico), poliacrilonitrila e resinas constituídas de estireno e divinilbenzeno, têm sido estudadas extensivamente ${ }^{18-21}$.

Os copolímeros de estireno-divinilbenzeno, conhecidos comercialmente como: Stryragel, Ultrastryragel, Ultrastyragel linear, SHODEX GPC, TSK GEL (tipo H), são materiais amplamente empregados em empacotamento de colunas para cromatografia de exclusão por tamanho (SEC). São formados por esferas minúsculas semi-rígidas obtidas por copolimerização em suspensão do estireno (STY) com divinilbenzeno (DVB), sendo compatíveis com muitos solventes orgânicos e apresentam boa resistência química e mecânica ${ }^{22}$.

Em trabalhos anteriores o copolímero de estirenodivinilbenzeno com concentrações moderadas de divinilbenzeno foi selecionado como suporte para imobilização da lipase microbiana (Candida rugosa) empregando heptano como meio de dispersão ${ }^{23,24}$. Esta metodologia favoreceu a obtenção de um complexo lipase-suporte com elevada atividade, cujas propriedades catalíticas foram consideradas adequadas tanto para conduzir reações de hidrólise como de esterificação, sendo ainda constatado uma elevada estabilidade operacional da lipase imobilizada (tempo de meia-vida de 620 horas) ${ }^{24}$. Resultados similares têm sido descritos por diversos pesquisadores, indicando uma nova tendência na utilização de solventes orgânicos apolares como meio de dispersão no procedimento de imobilização de lipases ${ }^{25-27}$.

Em função das características satisfatórias obtidas pela lipase imobilizada em STY-DVB, principalmente com relação a sua elevada estabilidade operacional, julgou-se conveniente um estudo mais detalhado referente a sua aplicação na síntese de ésteres aromatizantes. Como reação modelo, foi selecionado um sistema altamente polar constituído de n-butanol, ácido butírico em heptano como solvente. Foram determinadas as influências da razão molar entre ácido e álcool, massa de lipase imobilizada e da temperatura de reação no rendimento de formação do butirato de n-butila. Os dados obtidos foram comparados com os obtidos em estudos anteriores empregando uma preparação comercial de lipase imobilizada (Lipozyme) cujas propriedades catalíticas ${ }^{9,28}$, como alta atividade e estabilidade em temperaturas de até $60^{\circ} \mathrm{C}$, tornaram-na uma das mais testadas em escala de laboratório $9,12,28,29,31$.

\section{MATERIAIS E MÉTODOS}

\section{Materiais}

Foi utilizada lipase de origem microbiana (Candida rugosa) adquirida comercialmente da Sigma Co, EUA, contendo lactose (Candida rugosa lipase, Tipo VII), com atividade específica média de $1440 \mathrm{U} / \mathrm{mg}$ proteína. Como suporte de imobilização foi empregado copolímero de estireno-divinilbenzeno (STYDVB) contendo $45 \%$ de divinilbenzeno, de estrutura macroporosa, sintetizado por polimerização em suspensão utilizando $80 \%$ de diluição em heptano de acordo com metodologia desenvolvida no Instituto de Macromoléculas Profa. Eloisa Mano - UFRJ com as seguintes características ${ }^{32}$ : estrutura macroporosa, $45 \%$ DVB, granulometria 80 a 100 mesh; diâmetro médio de poro $291 \AA$; área BET $0,99 \mathrm{~m}^{2} / \mathrm{g}$; volume de poros 0,72 $\mathrm{cm}^{3} / \mathrm{g}$. Foram utilizados como materiais de partida n-butanol (Merck) e ácido butírico (Vetec) e agente dessecante peneira molecular (Aldrich $4 \AA$ ). Todos os outros reagentes foram de grau analítico.

\section{Imobilização da Lipase em STY-DVB}

O copolímero (4 gramas) foi suspenso em heptano $(20 \mathrm{~mL})$ durante 30 minutos sob agitação de $100 \mathrm{rpm}$. Em seguida, a lipase (1 grama) foi adicionada na mistura sob agitação e após 2 horas de adsorção, foi filtrada em tela de nylon de 420 mesh, sob pressão reduzida em funil de Buchner. As características gerais da preparação de lipase imobilizada em STY-DVB são apresentadas na Tabela 1. Informações detalhadas sobre esta metodologia de imobilização, bem como dados referentes à estabilidade operacional e de estocagem são encontrados nos trabalhos anteriormente realizados ${ }^{23,24}$.

Tabela 1. Caracterização da lipase imobilizada em STY-DVB

\begin{tabular}{lc}
\hline Tipo de suporte & $\begin{array}{c}\text { Copolímero de estireno - } \\
\text { divinilbenzeno } \\
\text { Adsorção física }\end{array}$ \\
Método de imobilização & $42 \%$ \\
Rendimento de imobilização $(\%)$ & $95-125$ \\
Atividade $(\mathrm{U} / \mathrm{mg}$ suporte seco) & $4-6 \%$ \\
Teor de água $(\%)$ & 7,5 \\
pH ótimo & 50 \\
Temperatura ótima $\left({ }^{\circ} \mathrm{C}\right)$ & 0,03 \\
Estabilidade térmica $\left(\mathrm{kd}, \mathrm{h}^{-1}\right)$ & 620 \\
Estabilidade operacional em reações & \\
de esterificação $\left(\mathrm{t}_{1 / 2}\right.$, horas) &
\end{tabular}

Fonte: Oliveira et ll. $^{23}$

\section{Procedimento das Reações de Esterificação}

As reações de esterificação foram conduzidas em reatores fechados de $100 \mathrm{~mL}$, contendo $20 \mathrm{~mL}$ de heptano previamente desidratado com sódio e quantidades apropriadas de nbutanol e ácido butírico. Foram estudadas as seguintes variáveis reacionais: razão molar de reagentes, massa de lipase imobilizada e temperatura de reação. No estudo da proporção molar de reagentes foram utilizados substratos com razões molares entre 0,5 e 3,0. As misturas foram incubadas com a lipase imobilizada $(115 \mathrm{U} / \mathrm{mg})$ numa proporção variável entre 5 e $60 \%$ em relação ao peso total de reagentes no meio reacional. Na determinação da influência da temperatura, a lipase imobilizada em STY-DVB foi utilizada na síntese do butirato de n-butila na faixa de temperatura entre 37 e $60^{\circ} \mathrm{C}$. Exceto para esses testes, todas as outras reações foram realizadas a $37^{\circ} \mathrm{C}$, sob agitação constante de $150 \mathrm{rpm}$, por um período mínimo de 24 horas. 


\section{Métodos Analíticos}

A concentração de n-butanol foi medida por cromatografia em fase gasosa (Cromatógrafo GC 37), empregando uma coluna empacotada (6ft S\# DEGS WHP 80/100 mesh), numa temperatura de $60^{\circ} \mathrm{C}$ e empregando hexanol como padrão interno. O teor de ácido butírico foi determinado por meio de titulação de alíquotas dissolvidas em etanol, empregando solução alcoólica de $\mathrm{KOH} 0,02 \mathrm{~N}$ e fenolftaleína como indicador. O grau de esterificação foi expresso em percentual molar do butanol consumido, empregando a equação 1:

$\%$ molar $=\frac{\mathrm{C}_{0}-\mathrm{C}}{\mathrm{C}_{0}} \times 100$

onde: $\mathrm{C}_{0}=$ concentração inicial do álcool e $\mathrm{C}=$ concentração do álcool em um determinado tempo.

A concentração de água nas fases líquida e sólida foi medida em um titulador automático Karl Fisher (Modelo Mettler DL 18). Os coeficientes de partição do suporte/reagentes foram estimados de acordo com a metodologia descrita anteriormente ${ }^{30}$, empregando a equação 2 :

$$
P=\frac{\mathrm{C}_{0}-\mathrm{C}}{\mathrm{C}} X \frac{V_{0}}{V-V_{0}}
$$

Onde: $P=$ coeficiente de partição do composto, $\mathrm{C}_{0}=$ concentração do composto na fase orgânica, $\mathrm{C}=$ concentração do composto após contato com suporte, $V_{0}=$ volume total (fase orgânica + suporte), $V=$ volume da fase orgânica. Para estimativa do volume do suporte $\left(V-V_{0}\right)$, foi construída uma curva de calibração do volume versus massa de suporte (volume da matriz $\left[\mathrm{cm}^{3}\right]=0,432 \times$ massa do suporte $(\mathrm{g})-0,085$, coeficiente de correlação $=0,999)$.

\section{RESULTADOS E DISCUSSÃO}

\section{Influência da Razão Molar}

$\mathrm{Na}$ síntese química de ésteres, geralmente é empregado excesso de ácido. Esta metodologia pode também ser aplicada na catálise enzimática em reações de esterificação. Entretanto, ácidos graxos de cadeia curta podem impor algum tipo de inibição no desempenho da lipase ${ }^{31}$. Para verificar o efeito do ácido butírico no desempenho da lipase imobilizada em STY-DVB, foram testadas relações molares entre ácido butírico $(\mathrm{AB})$ e n-butanol (ButOH) na faixa de 0,5 a 3,0. Como pode ser observado na Figura 1, quando excesso de ácido butírico foi usado nenhum efeito inibidor foi detectado na atividade enzimática. De fato, o progresso da reação de esterificação foi limitado pela disponibilidade de ácido butírico no meio reacional.

$\mathrm{Na}$ menor razão molar testada (AB:ButOH de 0,5$)$ foi alcançado um valor máximo da conversão de n-butanol na ordem de $24 \%$. Esta conversão foi otimizada com os aumentos proporcionais de ácido butírico no meio reacional. Razões molares iguais ou superiores a 1,5 forneceram conversões a produto superiores a $95 \%$. Para quantidades próximas da equimolaridade entre os reagentes, o rendimento foi a metade daquele quando empregou-se ácido em excesso.

Esta proporção entre os reagentes é similar à encontrada anteriormente para lipase imobilizada em silica de vidro de porosidade controlada (SPC) empregando o mesmo sistema reacional ${ }^{33}$. A razão para este fato pode estar relacionada com o caráter hidrofóbico dos suportes e similaridade entre os coeficientes de partição (medida da taxa de migração dos reagentes para a fase sólida) obtidos por as ambas preparações de derivados imobilizados: STY-DVB - Lipase e SPC-Lipase (Tabela 2).

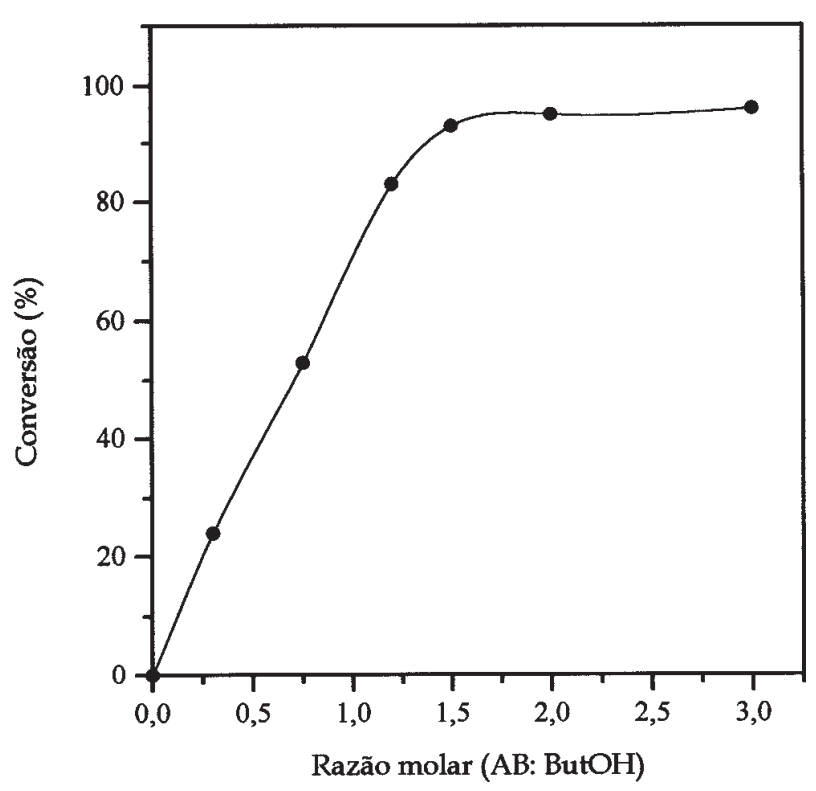

Figura 1. Influência da razão molar dos reagentes na conversão molar do n-butanol em produto. As reações foram incubadas com $250 \mathrm{mg} d a$ lipase imobilizada (115 U/mg) a $37^{\circ} \mathrm{C}$ por 24 horas empregando substratos numa concentração fixa de butanol $(200 \mathrm{mM})$ e concentrações de ácido butírico entre $100-600$ mM.

Tabela 2. Valores dos coeficientes de partição do n-butanol e ácido butírico para diferentes preparações enzimáticas.

\begin{tabular}{lcc}
\hline Reagente & \multicolumn{2}{c}{ Coeficiente de partição ${ }^{\mathrm{a}}$} \\
\hline & Lipase-STY-DVB & Lipase-SPC $^{\mathrm{b}}$ \\
n-Butanol & 2,32 & 1,97 \\
Ácido Butírico & 1,66 & 1,67 \\
\hline
\end{tabular}

$\bar{a}$ estimado de acordo com a equação 2 empregando soluções puras de cada composto em heptano, por 2 horas com agitação. ${ }^{\mathrm{b}}$ resultados descritos anteriormente ${ }^{33}$

Os valores indicados, mostram que as ambas preparações possuem valores de coeficientes de partição para o butanol mais elevados que os coeficientes de partição do ácido butírico, favorecendo desta maneira a migração do butanol para a fase sólida da enzima. Estes resultados sugerem que as matrizes usadas nas preparações enzimáticas possuem uma maior afinidade pelo butanol que pelo ácido butírico. Sendo assim, nas interfaces entre as lipases imobilizadas e o meio reacional deve haver mais álcool que ácido, levando à necessidade de que o meio contenha um excesso do ácido para que seja alcançado quantidades equimolares entre os reagentes e um rendimento satisfatório na reação de esterificação. Além disso, o excesso de ácido garante a formação do complexo enzima-grupo acila para posterior reação com o álcool, conduzindo assim à formação do éster, e reduzindo desta forma a competição entre os aceptores, parâmetro essencial para a cinética de uma reação de esterificação ${ }^{9,12}$. Isto sugere que a síntese de butirato de n-butila catalisada pela STY-DVB-Lipase pode ser limitada pela concentração de ácido butírico, levando à necessidade de se trabalhar com excesso deste reagente.

É interessante destacar que a atividade de esterificação está diretamente relacionada com os coeficientes de partição do substrato e produto de tal forma que esses valores podem ser usados como parâmetros para formulação do meio reacional. Esta metodologia tem sido aplicada com sucesso para estimar as razões molares para síntese do butirato de n-butila empregando lipase imobilizada em diferentes suportes ${ }^{27,30,33}$. 


\section{Influência da Massa de Lipase Imobilizada}

A conversão molar do n-butanol em produto, utilizando diferentes massas de lipase imobilizada em STY-DVB, foi avaliada em substratos constituídos de ácido butírico e butanol numa razão molar de 1,5 . As sínteses foram realizadas a $37^{\circ} \mathrm{C}$ e as massas de lipase imobilizada variaram entre $5 \%$ e $60 \%$ (80 a $1000 \mathrm{mg}$, respectivamente) da massa total dos reagentes contidos em $20 \mathrm{~mL}$ de substrato em heptano. Na Figura 2 a conversão molar do n-butanol em éster é plotada em função da massa de enzima e das unidades de atividades correspondentes. Valores iguais ou superiores a $15 \%$ da massa total de reagentes levaram a uma conversão quase completa do nbutanol em éster no período de 24 horas de reação. Essa concentração é semelhante a utilizada por diversos pesquisadores nos trabalhos experimentais com Lipozyme 12,29,30. $^{2}$

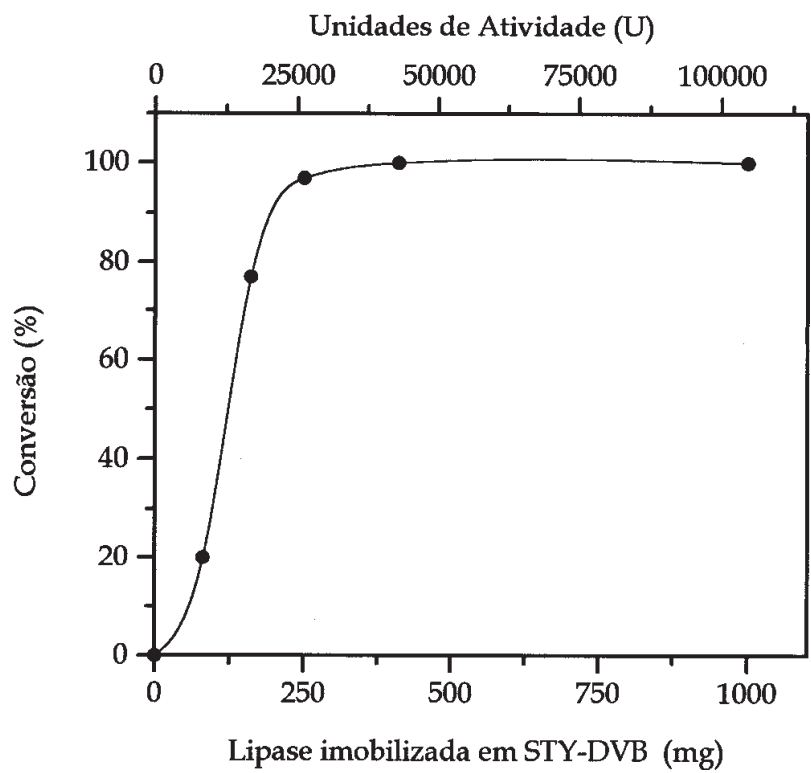

Figura 2. Influência da massa de lipase imobilizada na conversão molar de n-butanol a $37^{\circ} \mathrm{C}$ por 24 horas empregando $20 \mathrm{~mL}$ de substrato constituído de ácido butírico $(600 \mathrm{mM})$ e butanol $(400 \mathrm{mM}$ e $80 \mathrm{mg}$ (5\%), $160 \mathrm{mg}$ (10\%), 250mg (15\%), $410 \mathrm{mg}$ (25\%) e $1000 \mathrm{mg}$ (60\%) de lipase imobilizada em STY-DVB (115 U/mg).

\section{Influência da Temperatura de Reação}

Resultados anteriores ${ }^{23,24}$ mostraram que mediante a imobilização de lipase microbiana em STY-DVB, ocorreu uma modifícação em sua atividade lipolítica para valores mais altos de temperaturas ótimas. Este aumento de temperatura, correspondeu a um aumento na taxa de reação hidrolítica por unidade de enzima imobilizada. Para verificar a influência da temperatura na síntese do butirato de n-butila, experimentos foram efetuados numa faixa de temperatura entre 37 e $60^{\circ} \mathrm{C}$ Embora, um aumento de temperatura reacional em meio orgânico implique em uma maior estabilidade da lipase, tendo em vista que muitas das reações responsáveis pela desnaturação das enzimas são reações hidrolíticas, neste caso o aumento da temperatura promoveu um aumento na taxa de desativação térmica da lipase, reduzindo conseqüentemente a taxa de formação de produto. Como mostra a Figura 3, a conversão do n-butanol em produto diminuiu com o aumento da temperatura. A maior conversão, após 24 horas de reação, foi de $89 \%$ a $37^{\circ} \mathrm{C}$, e de $57 \%, 31 \%$ e $6 \%$, nas temperaturas de 45,50 e $60^{\circ} \mathrm{C}$, respectivamente. A partir destes resultados recomenda-se o uso da lipase imobilizada em STY-DVB em temperaturas iguais ou inferiores a $40^{\circ} \mathrm{C}$.

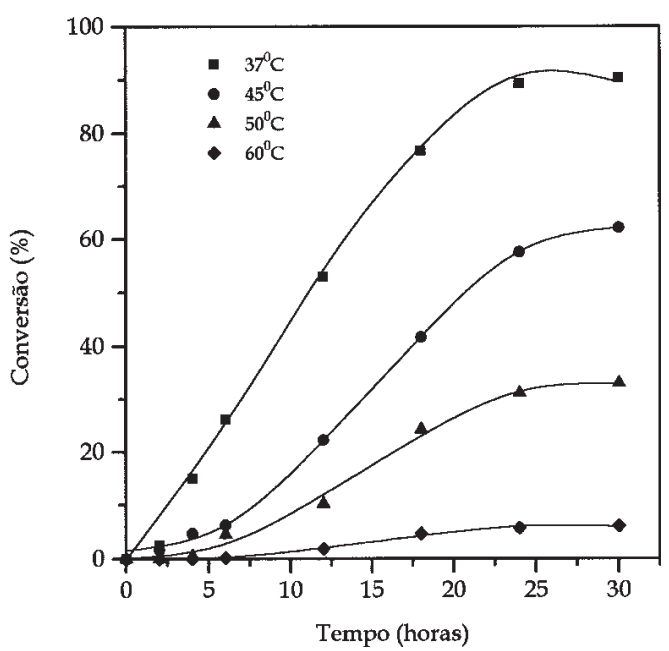

Figura 3. Efeito da temperatura na síntese do butirato de n-butila catalisada por lipase imobilizada em STY-DVB. $20 \mathrm{~mL}$ de substrato constituído de ácido butírico (600 mM) e n-butanol (400 mM) foi incubado com $500 \mathrm{mg}$ da lipase imobilizada (115 U/mg) nas temperaturas de $37-60^{\circ} \mathrm{C}$ por 24 horas.

Restrições semelhantes relativas à dependência do tempo na inativação térmica da lipase Candida rugosa são também encontradas na literatura. O trabalho desenvolvido por Battistel et al. ${ }^{34}$ é bem ilustrativo com relação ao mecanismo complexo que envolve a inativação térmica das Candidas lipases, mesmo em presença de polialcoóis, conhecidos como bons estabilizantes de enzimas.

\section{Comparação do Desempenho da Lipase Livre e Imobilizada na Síntese do Butirato de n-Butila}

A finalidade deste grupo de experimentos foi comparar o desempenho das lipases livre, imobilizada em STY-DVB e o da Lipozyme na síntese do butirato de n-butila. As sínteses foram realizadas à $37^{\circ} \mathrm{C}$ com substratos contendo ácido butírico e butanol na proporção molar de 1,5.

Os resultados apresentados na Figura 4, indicam que as taxas de conversão (expressas em $\mathrm{mM} / \mathrm{g} \cdot \mathrm{min}$ ), alcançadas nesta síntese pela lipase-STY-DVB foram cerca de cinco vezes inferiores a da lipase livre e sete vezes inferiores ao da Lipozyme.

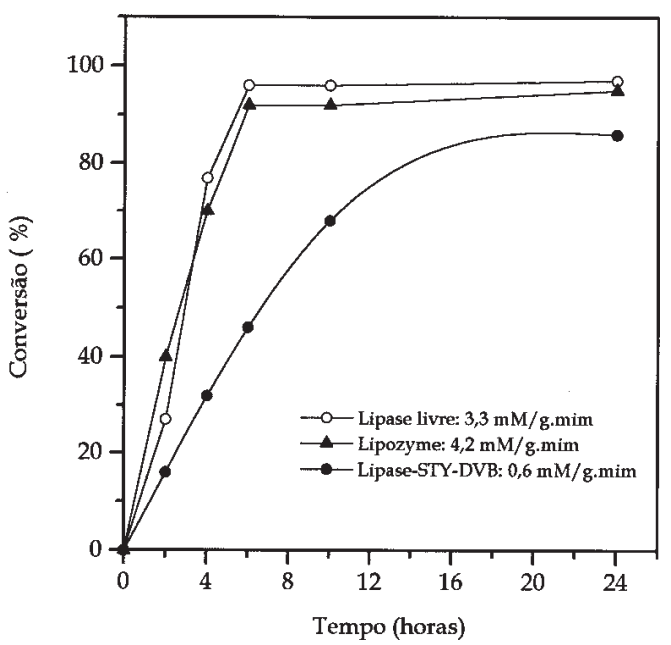

Figura 4. Comparação do desempenho da lipase livre, lipase imobilizada em STY-DVB e Lipozyme na formação do butirato de n-butila. As reações foram incubadas com $300 \mathrm{mg}$ da lipase livre, lipase imobilizada em STY-DVB e Lipozyme a $37^{\circ} \mathrm{C}$ por 24 horas empregando $20 \mathrm{~mL}$ de substrato constituído de ácido butírico $(450 \mathrm{mM})$ e n-butanol $(300 \mathrm{mM})$. 
Tabela 3. Diferenças básicas entre a Lipozyme (preparação comercial de lipase imobilizada) e lipase imobilizada em STY-DVB.

\begin{tabular}{lcc}
\hline Características & Lipozyme* & Lipase-STY-DVB \\
\hline Suporte & Resina aniônica & Resina hidrofóbica \\
Método de imobilização & Ligação iônica e adsorção & Adsorção \\
Fonte de enzima & Mucor miehei & Candida rugosa \\
\hline
\end{tabular}

*Dados descritos pelo fabricante ${ }^{9,28}$

Embora a Lipozyme tenha sido usada como parâmetro de comparação, esta metodologia não é totalmente adequada, tendo em vista as diferenças entre as preparações de lipase imobilizada, conforme indicado na Tabela 3. Além disso, o próprio fabricante (Novo Nordisk) ${ }^{28,35}$ relatou que tem uma experiência limitada na imobilização de Candida lipases em função das dificuldades de se obter preparações imobilizadas com alta atividade e estabilidade.

Com relação à comparação entre a Candida lipase na sua forma livre e imobilizada em STY-DVB, os resultados aparentemente indicam que a imobilização reduziu sensivelmente a atividade catalítica da enzima. Entretanto, deve ser considerado que a enzima na sua forma imobilizada pode ser utilizada durante um longo período com uma pequena perda de atividade (tempo de meia vida $=620$ horas) e a enzima livre após o uso é descartada ${ }^{22,23}$.

\section{CONCLUSÕES}

O derivado imobilizado em STY-DVB foi aplicado com sucesso na síntese do butirato de n-butila, apesar de ter apresentando um desempenho inferior ao alcançado pela Lipozyme (lipase imobilizada disponível comercialmente). A razão molar entre os materiais de partida foi um fator crítico para a obtenção de ésteres com altos rendimentos, requerendo um excesso de ácido butírico da ordem de 1,5 vezes com relação à concentração molar do nbutanol. O emprego de uma massa mínima de lipase imobilizada de $15 \%$ com relação ao total de reagentes envolvidos, garantiu a obtenção do produto com bons rendimentos de esterificação. A única restrição da preparação de lipase imobilizada é referente a sua baixa estabilidade térmica. São assim recomendadas temperaturas de incubação inferiores a $40^{\circ} \mathrm{C}$, para o uso pleno de sua atividade catalítica em reações de esterificação.

\section{AGRADECIMENTOS}

Os autores agradecem os auxílios recebidos do CNPq e FAPESP.

\section{REFERÊNCIAS}

1. Scott, C. D.; Scott, T. C.; Blanch, H. W.; Klibanov, A. M.; Russell, A. J.; In: Bioprocessing in Nonaqueous Media: Critical Needs and Opportunities. Oak Ridge National Laboratory, Report ORNL/TM -12849, 1996.

2. Jesus, P. C.; João, J. J.; Silva, P. I. F.; Burlin, G.; Nascimento, M. G.; Quim. Nova 1997, 20, 664.

3. Léon, R.; Fernades, P.; Pinheiro, H. M.; Cabral, J. M. S.; Enzyme Microb. Technol. 1998, 23, 483.

4. Roberts, S. M.; Turner, M. K.; Enantiomer 1998, 3, 9.

5. Zaks, A.; Klibanov, A. M.; J. Biol. Chem. 1988, 263, 8017.

6. Faber, K.; In: Biotransformations in Organic Chemistry: A Textbook, 3rd Edition, Springer ProduktionsGesellschaft, Berlin, 1997.

7. Monot, F.; Revue de L'Institut Français du Pétrole 1994, $49,2$.
8. Lima, A. W. O.; Angnes, L.; Quim. Nova 1999, 22, 229.

9. de Castro, H. F.; Anderson, W.; Quim. Nova 1995, 18, 544.

10. Paiva, A. L; Malcata, F. X.; J. Mol. Catalysis BEnzymatic 1997, 3, 99.

11. Gandhi, N. N.; J. Am. Oil Chem. Soc. 1997, 74, 621.

12. Yahya, A. R. M.; Anderson, W. A.; Moo-Young, M.; Enzyme Microb. Technol. 1998, 23, 438.

13. Balcão, V. M.; Paiva, A. L.; Malcata, F. X.; Enzyme Microb. Technol. 1996, 18, 392.

14. Reslow, M.; Adlercreutz, P.; Mattiason, B.; Europ. J. Biochem. 1988, 172, 573 .

15. Malcata, F. X.; Reyes, H. R.; Garcia, H. S.; Hill Jr, C. G.; Amundson, C. H.; J. Am. Oil Chem. Soc. 1990, 67, 890.

16. Ison, A. P.; Macrae, A. R.; Smith, C. G.; Bosley, J.; Biotechnol. Bioeng. 1994, 43,122.

17. Bastida, A.; Sabuquillo, P.; Armisen, P.; FernándezLafuente, R.; Huguet, J.; Guisán, J. M.; Biotechnol. Bioeng. 1998, 50, 486.

18. Arroyo, M.; Sánches-Montero, J. M.; Sinisterra, J. V. Enzyme Microb. Technol. 1999, 24, 3.

19. Matsumoto, M.; Sumi, N.; Ohmori, K. ; Kondo, K.; Process Biochem. 1998, 33, 535.

20. Bryjak, J.; Bachamann, K.; Pawlow, B.; Maliszewska, I.; Trochimczuk, A.; Kolarz, B. N.; Chem. Eng. J. 1997, $65,249$.

21. Mojovic, L.; Knezevic Z.; Popadic, R.; Jovanovic, S.; Appl. Microb. Biotechnol. 1998, 50, 676.

22. Ruckenstein, E; Wang, X.; Biotechnol. Bioeng. 1993, 42,821 .

23. Oliveira, P. C.; Dissertação de Mestrado, UNICAMP, 1999.

24. Oliveira, P. C.; Alves, G. M.; de Castro, H. F.; Biochem. Eng. J. 2000, 5, 63.

25. Fukunaga, K.; Minamijima, N.; Sugimura, Y.; Zhang, Z.; Nakao, K.; J. Biotechnol. 1996, 52, 81.

26. Nakagawa, H.; Watanabe, S.; Shimura, S.; Kirimura, K.; Usami, S; World J. Microb. Biotechnol. 1998, 14, 219.

27. de Castro, H. F.; Oliveira, P. C.; Zanin, G. M.; Soares, C. M. F.; J. Am. Oil Chem. Soc. 1999, 76, 147.

28. Novo Nordisk. Product Information. B-347b- GB, 1986.

29. de Castro, H. F.; Pereira, E. B.; Anderson, W. A.; J. Braz. Chem. Soc. 1996, 7, 219.

30. de Castro, H. F.; Oliveira, P. C.; Soares, C. M. F.; C. Tecnol. Alim. 1997, 17, 237.

31. de Castro, H. F.; Oliveira, P. C.; Pereira, E. B.; Biotechnol. Lett. 1997, 19, 229.

32. Neves, M. A. F. S. Dissertação de Mestrado, Instituto de Macromoléculas Prof. Eloisa Mano, UFRJ, 1996.

33. Soares, C. M. F.; de Castro, H. F.; de Moraes, F. F.; Zanin, G. M.; Appl. Biochem. Biotechnol. 1999, 77/79, 745.

34. Battistel, E.; Biachi, D.; Accunzo, A. D.; Alteris, E.; Parascandola, P.; Appl. Biochem. Biotechnol. 1995, 50, 161.

35. Eigtved, P.; Hansen, T.; Sakaguchi, H. Characteristics of Immobilized Lipase in Ester Synthesis and Effects of Water and Temperature in Various Reations. In AOCS/ JOCS Meeting, Honolulu, 1986. 